\title{
MOLECULAR IDENTIFICATION OF ROTAVIRUS STRAINS ASSOCIATED WITH DIARRHEA AMONG CHILDREN IN KWARA STATE, NIGERIA
}

\author{
* Kuta ${ }^{1}$, F.A., Uba ${ }^{2}$, A., Nimzing ${ }^{3}$, L. and Damisa, ${ }^{1}$ D. \\ ${ }^{1}$ Department of microbiology, federal university of Technology, Minna, Nigeria. \\ ${ }^{2}$ Biological sciences programme, Abubakar Tafawa Balewa university, Bauchi, Nigeria. \\ ${ }^{3}$ Department of Medical Microbiology, University of Jos teaching Hospital, Jos, Nigeria.
}

\begin{abstract}
The study was carried out to determine the molecular characteristics of the rotavirus strains associated with diarrhea among children in Kwara state, Nigeria. A total of 150 stool samples were collected from diarrheic children. The stool samples were screened for rotavirus, using Enzyme linked Immunosorbent assay (ELISA). Nine (9) stool samples were positive 6\%. The prevalence of rotavirus infection according to sex was as follows: Male 3.30\% and Female 2.70\%. The distribution of infection according to age of the children was as follows; <1-2 years 4\% and 3-5 years had 2\%. The prevalence of infection in dry months was $4.7 \%$ while in wet months it was 1.3\%. Chi-square test revealed that there was no relationship between the rate of infection and factors such as age and sex of the children except seasonal variations. Molecular identification of the virus indicated P4, P6, G1 and G8 as the common genotypes of rotavirus in Kwara State. More hospital and community base investigations should be conducted to ascertain the diversity of the virus in Kwara State.
\end{abstract}

Keywords: Genotypes, prevalence, rotavirus, gastro-enteritis, Enzyme linked immunosorbent, Kwara State.

\section{INTRODUCTION}

Rotavirus is a double stranded RNA virus in the family of Reoviridae. It is the leading cause of severe diarrhea among children (Dennehy, 2008). Over 870,000 children (0-5 years) die annually due to rotavirus gastroenteritis worldwide. Studies conducted in Nigeria revealed high prevalence of rotavirus gastroenteritis (Gomwalk et al.,1993; Aminu et al., 2009). An estimated number of children that die annually in Nigeria due to rotavirus gastroenteritis is about 33,000 . Effort have been made to reduce the disease burden through vaccine development, but it has been hampered due to continuous emergence of new strains particularly in Africa (Aminu et al., 2009). This ugly situation has continued to hinder the development of potent vaccine that could be used to stem the scourge in Nigeria and indeed other developing nations. Therefore, this study was aimed at identifying the genetic diversity of the rotavirus associated with diarrhea in Kwara state.

\section{MATERIALS AND METHODS}

\section{Study area}

Kwara State was created on 27 May, 1967, when the Federal Military Government of General Yakubu Gowon broke the four regions that then constituted the federation of Nigeria into 12 states. At its creation, the state was made up of the former Ilorin and Kabba provinces of the then Northern region and was inintially named the west central State but later changed to Kwara a local name for the river Niger. The State has 16 local government areas with human population of 2,591,555 (2006 Census).

\section{Sample Collection}

One hundred and fifty (150) stool samples were collected from diarrheic children (0-5years) in both dry and rainy seasons at the Paediatric Departments of five hospitals located in Kwara State. The stool samples collected were transported to the Center for Biotechnology Research and Training, ABU, Zaria and stored in the temperature regulated refrigerator at $20^{\circ} \mathrm{C}$ for further analysis (Aminu et al., 2009)

Preparation of Frozen Stool Samples for Enzyme linked Immunosorbent Assay

The one hundred and fifty frozen stool samples were thawed and each diluted to a ratio of $1: 5$ by adding 1 gram of stool sample to $4 \mathrm{ml}$ of dilute wash buffer in each case. These were mixed thoroughly and allowed to settle. The supernatants were collected and used for Enzyme linked immunosorbent assay (Aminu et al., 2009).

All the one hundred and fifty stool samples were screened as follows: One hundred microliter of positive control reagent was introduced into well two and three of the 96 titre plates. Hundred microliter of negative control reagent was introduced into well four and five. Hundred microliter of supernatant phase of the 150 stool samples were introduced into well six to the $96^{\text {th }}$ well separately. The plates were incubated at room temperature for 30 minutes. The wells were washed with dilution buffer solution. Two drops of reagent one (blue solution) was introduced into each of the wells except well one (blank). The plates were then incubated at room temperature for 5 minutes and was rinsed with wash buffer. 
Two drops of reagent two (red solution) was introduced into each well and incubated at room temperature for 5 minutes and washed again. Two drops of chromogen was added to each well and was mixed thoroughly. Finally, two drops of stop solution was added into each well and was mixed. Visual observation and readings from spectrophotometric and bichromatic device was carried out and recorded.

\section{Extraction of RNA}

Enzyme linked immunosorbent assay positive stool samples were subjected to rotavirus RNA extraction as follows (Aminu et al., 2009):

Three hundred (300) microliter of lysis buffer was added to 100 microliter of each diluted positive stool sample. The mixture was transferred to collection tube and centrifuged at $12,000 \mathrm{rpm}$ for 2 minutes. The flow through from the collection tubes was discarded. 300 microliter RNA wash buffer was added to the column and was centrifuged at $12,000 \mathrm{rpm}$ for 30 seconds. The flow through was again discarded and the zymospin column tubes were placed into the collection tubes. 300 microliter of RNA wash buffer was added to the column tubes, spinned at $12,000 \mathrm{rpm}$ for 30 seconds, and the flow through from the collection tubes was also discarded. The zymospin column tubes were further spinned at $12,000 \mathrm{rpm}$ for one minute in an empty collection tube in order to ensure complete removal of the wash buffer (Aminu et al., 2009).

The zymospin column tubes were placed into RNase free tubes. 10 microliter of the RNase free water was introduced into the column tubes and the mixture was allowed to stand at room temperature for one minute. The mixture was then centrifuged at $12,000 \mathrm{rpm}$ for one minute to elute the viral RNA from stool samples and was used immediately for the generation of cDNA for VP7 and VP4 genes of the virus (Aminu et al., 2009)

\section{Generation of VP7 CDNA}

Eight (8) microliter of the RNA was introduced into 500 microliter PCR tubes. One microliter primer pairs (Beg 9 and End 9) was introduced into PCR tubes. The mixture was heated to $95^{\circ} \mathrm{C}$ for 5 minutes to denature the dsRNA and was cooled on ice immediately for 2 minutes. One microliter reverse transcriptase (RT) was introduced into the mixture. Finally the mixture was centrifuged at $10,000 \mathrm{rpm}$ for one minute and was incubated at $42^{\circ} \mathrm{C}$ for 30 minutes for the generation of cDNA (Aminu et al., 2009).

\section{Generation of VP4 CDNA}

Eight (8) microliter of the extracted RNA was introduced into 500 microliter PCR tubes. One microliter each of the primer pairs (con2 and con3) were introduced into PCR tubes. The mixture of the RNA and primer was heated to $95^{\circ} \mathrm{C}$ for 5 minutes to denature the dsRNA and was cooled on ice immediately for 2 minutes. Reverse transcriptase (RT) was introduced into the mixture. Finally the mixture was centrifuged at $10,000 \mathrm{rpm}$ for one minute and was incubated at $42^{\circ} \mathrm{C}$ for 30 minutes for the generation of cDNA (Aminu et al., 2009).

\section{Preparation and Casting of gel}

Twenty milliliter $(20 \mathrm{ml})$ tris acetase buffer (TAE) was mixed with $80 \mathrm{ml}$ of distilled water to make $100 \mathrm{ml}$. Two grammes of agarose was weighed and dissolved into the solution. The mixture was heated at $85^{\circ} \mathrm{C}$ for 2 minutes. The gel was allowed to cool to $45^{\circ} \mathrm{C}$, after which 10 microliter ethidium bromide was added and allowed to diffuse into the gel. The gel was poured onto the gel cassette tray with a comb in place. The gel was allowed to set at room temperature for 45 minutes. The tray was submerged beneath TAE running buffer in an electrophoresis apparatus and the comb removed (Aminu et al., 2009).

\section{Loading of the Gel}

Ten (10) microliter of each cDNA product was mixed with loading dye and loaded into seperate wells on the gel. The first and the last well of the gel were loaded with 1 kilobase DNA ladder.

The gel was electrophoresed at $100 \mathrm{~V}$ for 45 minutes at room temperature. The electrophoretic apparatus was switched off and the gel was removed, it was viewed first under UV - light and the image captured using gel documentation machine (Aminu et al., 2009).

\section{Amplification of VP7 CDNA}

Eight (8) microliter of the VP7 CDNA was introduced into 500 microliter PCR tube. Two microliter RNA water was added and mixed. In addition to the mixture, 15 microliter of the PCR master mix was introduced to the PCR tubes. Finally one microliter of each of the G-genotypes specific primers and 2 microliter of consensus primer such as Beg 9 and End 9 were added to the mixture. The samples were amplified in PCR machine programmed to run 30 cycles (Aminu et al., 2009).

\section{Amplification of VP4 CDNA}

Eight (8) microliter of the VP4 CDNA was introduced into 500 microliter PCR tube: Two microliter RNA water was added and mixed. In addition to the mixture, 15 microliter of the PCR master mix was introduced to the PCR tubes. Finally one microliter of each of the P-genotypes specific primers and 2 microliter of consensus primer such as Con 2 and Con 3 were added to the mixture. The samples were amplified in PCR machine programmed to run 30 cycles (Aminu et al., 2009).

Two percent (2\%) agarose gel containing 10 microliter ethidium bromide was prepared and casted. Ten microliter of each of cDNA product was mixed with loading dye and loaded into separate wells on the gel. The first and the last well of the gel were loaded with 1 kilobase DNA ladder (Aminu et al., 2009).

The gel was electrophoresed at $100 \mathrm{~V}$ for 45 minutes at room temperature. The electrophoretic apparatus was switched off and the gel was removed, it was viewed under UV-light and the image captured using gel documentation machine (Aminu et al., 2009). 


\section{Statistical analysis}

The data generated was analysed using the percentage positive frequency technique and the values were compared to the chi-square value. The level of significance was tested at $95 \%$ confidence level.

\section{RESULTS}

Out of the 150 stool sample screened for rotavirus using ELISA only 9 were positive, representing $6 \%$. The prevalence of rotavirus infection among children according to sex was as follows: Male (3.30\%) and female $(2.70 \%)$ (Table 1$)$.

Table 1: Incidence of Rotavirus diarrhea according to sex of the children

\begin{tabular}{cccc}
\hline Sex & $\begin{array}{c}\text { Number of samples } \\
\text { collected }\end{array}$ & $\begin{array}{c}\text { Number of positive } \\
\text { samples }\end{array}$ & Prevalence (\%) \\
\hline Male & 70 & 5 & 3.30 \\
Female & 80 & 4 & 2.70 \\
\hline Total & 150 & 9 & 6.0 \\
\hline
\end{tabular}

The incidence of rotavirus diarrhea according to age of the children in Kwara State was as follows $<1-2$ years (4\%) and 3-5years had (2\%) (Table 2).

Table 2: Incidence of Rotavirus diarrhea according to age of the children

\begin{tabular}{cccc}
\hline Age (years) & $\begin{array}{c}\text { Number of samples } \\
\text { collected }\end{array}$ & $\begin{array}{c}\text { Number of positive } \\
\text { samples }\end{array}$ & Prevalence (\%) \\
\hline$<1-2$ & 90 & 6 & 4.0 \\
$3-5$ & 60 & 3 & 2.0 \\
\hline Total & 150 & 9 & 6.0 \\
\hline
\end{tabular}

The prevalence of rotavirus diarrhea according to season was distributed as follows; Dry months (4.70\%) and Wet months (1.30\%) (Table 3).

Table 3: Incidence of Rotavirus diarrhea according to season of sample collection

\begin{tabular}{cccc}
\hline Season & $\begin{array}{c}\text { Number of samples } \\
\text { collected }\end{array}$ & $\begin{array}{c}\text { Number of positive } \\
\text { samples }\end{array}$ & Prevalence (\%) \\
\hline Dry months & 80 & 7 & 4.70 \\
Wet months & 70 & 2 & 1.30 \\
\hline Total & 150 & 9 & 6.0 \\
\hline
\end{tabular}

Frequency occurrence of the different rotavirus genotypes was as follows; P4 (33\%), P6 (33\%), G1(11\%) and G8 (22\%) (Table 4).

Table 4 Strains of Rotavirus prevalent in Kwara State

\begin{tabular}{lll}
\hline Genotypes & Frequency & Percentage (\%) \\
\hline P4 & 3 & 33 \\
P6 & 3 & 33 \\
G1 & 1 & 11 \\
G8 & 2 & 22 \\
\hline Total & 9 & 99 \\
\hline
\end{tabular}

\section{DISCUSSION}

In this study, 150 stool samples were collected from diarrheic children (0-5years) in Kwara State. The stool samples were screened for rotavirus and the overall prevalence was $6 \%$. Higher prevalence of $27 \%$ has been reported in previous studies (Gomwalk et al., 1990; Gomwalk et al., 1993 ). This could be attributed to poor hygienic practices and poor environmental management in the past. Several studies (Glass et al.,2006 ; Armah et al., 2003; Aminu et al., 2009) have reported that rotavirus gastroenteritis has no link to the quality of environment. It will not be out of place to argue that poor sanitary condition can encourage the transmission of diarrhea particularly among infants and young children

The prevalence of rotavirus infection among male children was $3.30 \%$ and female was $2.70 \%$ (Table 1). Although there seem to be difference between the prevalence in male children, but chisquare test revealed that it was not significant at $P>$ 0.05 . Studies by Glass et al. (2006) and Aminu et al. (2009) have reported that male children are more vulnerable to rotavirus gastroenteritis. In this case there was no significant difference. This makes the result different from the previous works.

The prevalence of rotavirus gastroenteritis among children between $<1-2$ years $(4 \%)$ and those within 3-5 years recorded $2 \%$ (Table 2 ). Studies by Glass et al. (2006) and Armah et al. (2003) have established in their reports that infants and young children are more susceptible to rotavirus gastroenteritis. This could be used to explain the high prevalence recorded among the lowest age group ( $<1-2$ years) in this study. However, chi-square test indicated that there was no significant difference $(P>$ 0.05). 
The prevalence of rotavirus gastroenteritis among children in the study area with respect to seasonal variation was as follows; dry months (4.70\%) and rainy season $(1.30 \%)$ (Table 3 ). Several studies (Paul and Erinle,1982; Glass et al. 2006;Armah et al. 2003; Aminu et al; 2009) have reported high prevalence of gastroenteritis among children during winter. In this study similar trend was observed as reported in

\section{REFERENCES}

Aminu, M., Esona, M. D., Geyer, A. and Steele, A. D. (2009). Epidermiology of Rotavirus and Astrovirus Infections in Children in Northwestern Nigeria. Annals of African Medicine 7(4): 168-174.

Armah, G. E., Steele, A. D., Binka, F. N., Esona, N. D., Asmah, H. R., Anto, F., Brown, D., Green, J., Cutts, F. and Hall, A. (2003). Changing Patterns of Rotavirus Genotype in Ghana: Emergence of Human Rotavirius G9 as a Major Cause of Diarrhoea in Children. Journal of Clinical Microbiology 41(6): 2317-2322.

Dennely, P. H. (2008). Rotavirus Vaccines: An overview. Clinical Microbiology Review 21(1): 198-208

Glass, R. I., Bresse, J. S., Jiang, B., Parashar, U. D., Yee, E. and Gentsch, J. R. (2006). Rotavirus and Rotavirus Vaccines. Hot topics in Infection and Immunity in Children 5: 45-54.

Gomwalk, N. E., Gosham, L. T. and Umoh, U. J. (1990). Rotavirus Gastroenteritis in Pediatrics Diarrhoea in Jos, Nigeria. Journal of Tropical Pediatrics 36(2): 52-57 previous studies. The outcome of this study conform with the previous reports. The strains of rotavirus identified in Kwara state seems to be the strains that are commonly found worldwide (Table 4). This could be attributed to their high adaptive capacity as reported by Mishra et al., (2010). The results of this study suggest that all the socio-economic factors considered have no significant relationship with the rate of infections.

Gomwalk, N. E.,Umoh, U. J., Gosham, L. T. and Ahmad, A. A. (1993). Influence of Climatic Factors on Rotavirus Infection among Children with Acute Gastroenteritis in Zaria, Northern Nigeria. Journal of Tropical Pediatrics 39(5): 293-297.

Mishra, V., Awasthi, S., Nag, V. L. and Tandon, R. (2010). Genomic Diversity of Group A Rotavirus Strains in Patients Aged $1-36$ Months Admitted for Acute Watery Diarrhea in Northern India; a Hospital Based Study. Journal of Clinical Microbiology and Infectious Diseases. 16(1), 45 -50

Paul, M. O. and Eraile, E. A. (1982). Influence of Humidity on Rotavirus Prevalence among Nigerian Infants and Young Children with Gastroenteritis. Journal of Clinical Microbiology 15(2): 212-215. 